\title{
COMPETENCIA PARA CONOCER DE UNA DEMANDA DE OPOSICIÓN A LA EJECUCIÓN DE UNA RESOLUCIÓN EXTRANJERA SOBRE ALIMENTOS: A PROPÓSITO DE LA SENTENCIA DEL TJUE 4 DE JUNIO DE 2020, FX C. GZ, C-41/19
}

\author{
JURISDICTION TO RULE ON AN APPLICATION OPPOSING \\ ENFORCEMENT OF A FOREIGN MAINTENANCE DECISION: \\ PURPOSE TO THE CJEU JUDGEMENT OF 4TH JUNE 2020, FX
} C. GZ, C-41/19

\author{
María José Castellanos Ruiz \\ Profesora Ayudante Doctora de Derecho Internacional Privado \\ Universidad Carlos III de Madrid \\ ORCID ID: 0000-0003-1869-4488
}

Recibido: 20/12/2020 / Aceptado:

DOI: https://doi.org/10.20318/cdt.2021.5990

\begin{abstract}
Resumen: La Sentencia del TJUE de 4 de junio de 2020, FX c. GZ, C-41/19, resuelve la cuestión de si la demanda de oposición a la ejecución de una resolución extranjera en materia de alimentos, por parte del deudor de dichos alimentos, se encuentra dentro del ámbito de aplicación del Reglamento 4/2009. Pues bien, en primer lugar, el TJUE tiene que decidir si se trata de un asunto que se encuentra del capítulo II del Reglamento 4/2009, que regula la competencia judicial internacional; o, se incluye dentro del capítulo IV, con lo cual serían de aplicación al litigio las normas sobre reconocimiento y ejecución de resoluciones; o bien se excluye del ámbito de aplicación del Reglamento 4/2009 y pudiera ser de aplicación el Reglamento 1215/2012.

En segundo lugar, el TJUE ha de resolver la competencia para conocer de una demanda de oposición a la ejecución por parte del deudor de alimentos, cuando el motivo en el que se basa dicha demanda de oposición a la ejecución es la liquidación de la deuda.
\end{abstract}

Palabras clave: Reglamento 4/2009, competencia, demanda de oposición a la ejecución, alimentos, liquidación de deuda.

Abstract: The CJEU Judgement of 4th June 2020, FX c. GZ, C-41/19, resolves the question of whether the application opposing enforcement of a foreign maintenance decision by the debtor of said maintenance obligation, is within the scope of Regulation 4/2009. Well, first of all, the CJEU has to decide whether it is a matter that falls under chapter II of Regulation 4/2009, which regulates jurisdiction; or, it is included in chapter IV, with which the rules on recognition and enforcement of decisions would be applicable to the litigation; or it is excluded from the scope of Regulation 4/2009 and Regulation 1215/2012 could be applicable.

Second, the CJEU has to resolve the jurisdiction to rule on an application opposing enforcement by the maintenance debtor, when the reason on which said of a foreign maintenance decision is based is the discharge of the debt.

Keywords: Regulation 4/2009, jurisdiction, application opposing enforcement, maintenance obligation, discharge of the debt 
Sumario: I. Introducción de la STJUE 4 junio 2020, FX c. GZ, C-41/19: 1. Hechos. 2. Cuestión prejudicial. II. Competencia para conocer de una demanda de oposición a la ejecución realizada contra una resolución de alimentos extranjera. 1. Ámbito de aplicación del Reglamento 4/2009. 2. Tribunales competentes en relación a una demanda de oposición a la ejecución basada en la liquidación de la deuda de alimentos (art. 41.1 Reglamento 4/2009). III. Conclusiones.

\section{Introducción de la STJUE 4 junio 2020, $f x$ c. $G z, c-41 / 19^{1}$}

1. La STJUE 4 junio $2020, F X$ c. GZ, C-41/19 ha sido dictada como respuesta a la cuestión prejudicial planteada por el Amtsgericht Köln -Tribunal de lo Civil y Penal de Colonia, Alemania-, en el marco de un litigio en relación con una demanda de oposición a la ejecución de una resolución de alimentos polaca. En dicha controversia, el demandante es FX, deudor de alimentos, con domicilio en Alemania; mientras que la demandada es GZ, acreedora de alimentos e hija del demandante, con domicilio en Polonia.

La cuestión prejudicial se plantea con el fin de determinar si la citada demanda de oposición a la ejecución de una resolución de alimentos, por parte del deudor de dichos alimentos, se encuentra dentro del ámbito de aplicación del Reglamento (CE) núm. 4/2009, sobre competencia judicial internacional y reconocimiento y ejecución de resoluciones judiciales en materia de alimentos; en adelante Reglamento $4 / 2009^{2}$. Si la respuesta fuese negativa, habría que plantearse la cuestión de si dicha demanda del deudor de alimentos podría estar dentro del ámbito de aplicación del Reglamento (UE) núm. 1215/2012, en relación a la competencia judicial internacional y reconocimiento y ejecución de resoluciones judiciales en materia civil y mercantil; que será denominado en adelante Reglamento 1215/2012 .

\section{Hechos}

2. El demandante en el presente asunto reside en Alemania; mientras que la demandada es una hija a cargo, representada por su madre, que reside en Polonia.

Mediante resolución de 26 de mayo de 2009, la demandada obtuvo de los tribunales polacos una resolución que declaraba la obligación alimenticia de su padre (el demandante), residente en Alemania ${ }^{4}$. Tras conseguir, mediante auto de 27 de julio de 2016, que se declarase la fuerza ejecutiva de la resolución polaca en materia de alimentos en Alemania, la demandada solició la ejecución de dicha resolución en este último Estado miembro 5 .

Sin embargo, mediante solicitud presentada el 5 de abril de 2018 ante el órgano jurisdiccional alemán, el demandante se opone a la ejecución de la resolución, alegando que ya ha cumplido en su mayor parte sus obligaciones de pago. Afirma que él mismo ha efectuado pagos de alimentos y que la demandada ha percibido, además, asignaciones públicas a través del fondo de prestación de alimentos polaco en su nombre, dentro del límite de su capacidad económica ${ }^{6}$.

${ }^{1}$ STJUE 4 de junio de 2020, FX c. GZ, C-41/19 (ECLI:EU:C:2020:425).

${ }^{2}$ Reglamento (CE) núm. 4/2009 del Consejo, de 18 de diciembre de 2008 (DO núm. L 7, 10 enero 2009), relativo a la competencia, la ley aplicable, el reconocimiento y la ejecución de las resoluciones y la cooperación en materia de obligaciones de alimentos

${ }^{3}$ Reglamento (UE) núm. 1215/2012 del Parlamento Europeo y del Consejo, de 12 de diciembre de 2012 (DO núm. L 351, 20 diciembre 2012), relativo a la competencia judicial, el reconocimiento y la ejecución de resoluciones judiciales en materia civi y mercantil.

${ }^{4}$ El demandante fue condenado a abonar a su hija una pensión alimentaria de 500,00 eslotis polacos (PLN) mensuales a partir del 1 de septiembre de 2008 y, retroactivamente, un importe de 430,00 PLN mensuales para el período comprendido entre el 19 de junio de 2008 y el 31 de agosto de 2008 (Conclusiones del Abogado General, Sr. M. Bobek, presentadas el 27 de febrero de 2020, FX c. GZ, C-41/19 (ECLI:EU:C:2020:132), apartado 19).

${ }^{5}$ Conclusiones del Abogado General, Sr. M. Bobek, presentadas el 27 de febrero de 2020, FX c. GZ, C-41/19 (ECLI:EU: C:2020:132), apartado 21.

${ }^{6}$ El demandante señala concretamente que entre 2008 y 2010 inclusive, abonó en concepto de alimentos un total de 6640,05 PLN y, además, desde diciembre de 2010, la demandada ha percibido asignaciones públicas por una cantidad de 
3. Para el tribunal alemán, que conoce del asunto, la demanda de oposición a la ejecución es un asunto en materia de alimentos conforme al Reglamento 4/2009, aunque no tiene competencia para conocer del asunto en virtud de los foros generales de competencia de su art. $3^{7}$. En su opinión, son los tribunales polacos, los que estarían en mejor situación de comprobar las alegaciones del demandante, en virtud de los foros recogidos en los arts. 3.a) y 3.b) del Reglamento $4 / 2009^{8}$.

Sin embargo, el órgano jurisdiccional alemán considera que no puede declararse de oficio incompetente en virud del art. 10, porque la demanda de oposición a la ejecución no se menciona expresamente ni en el Reglamento 4/2009, ni en el Reglamento 1215/2012; mientras que la acción de modificación de una resolución judicicial, sí que se contempla en el art. 8 del Reglamento 4/2009 . Por eso plantea como primera cuestión prejudicial si dicha demanda de oposición a la ejecución estaría dentro del ámbito de aplicación del Reglamento 4/2009.

En el supuesto de que el Tribunal de Justicia responda negativamente a dicha cuestión, con su segunda cuestión prejudicial el órgano jurisdiccional alemán desea saber, si su competencia se puede fundamentar en el art. 24.5 del Reglamento 1215/2012, que recoge la competencia de los órganos jurisdiccionales del Estado miembro del lugar de ejecución, por tratarse de un procedimiento en materia de ejecución de resoluciones judiciales ${ }^{10}$. Si bien, en virtud del art. 1.2.e) del Reglamento 1215/2012, este no es de aplicación a las obligaciones de alimentos.

\section{Cuestión prejudicial}

4. Como consecuencia de los hechos relacionados, el Amtsgericht Köln -Tribunal de lo Civil y Penal de Colonia, Alemania- decidió suspender el procedimiento y plantear al Tribunal de Justicia de la Unión Europea dos cuestiones prejudiciales ${ }^{11}$.

De forma acertada, el Abogado General, Sr. M. Bobek, considera que la aplicabilidad del Reglamento 4/2009 no implica que el órgano jurisdiccional alemán sea incompetente. Por lo que es preciso aclarar, en primer lugar, si el Reglamento 4/2009 es aplicable en la fase de ejecución de las resoluciones en materia de alimentos, lo cual parece descartar el tribunal alemán. Después de llegar a la conclusión de que el Reglamento 4/2009 es aplicable en la fase de ejecución, y de que es consustancial al sistema de dicho Reglamento que la competencia corresponda a los órganos jurisdiccionales del Estado miembro de ejecución, se analizará la cuestión concreta, esto es la competencia para conocer de una demanda de oposición a la ejecución basada en la liquidación de la deuda ${ }^{12}$.

5. En definitiva, dichas cuestiones prejudiciales versan sobre la citada demanda de oposición a la ejecución, basada en la liquidación de la deuda y presentada por el demandante ante los órganos jurisdiccionales alemanes. Así pues, la cuestión fundamental que se plantea puede resumirse en una, que

500 PLN mensuales a través del fondo de prestación de alimentos polaco. El demandante afirma que el fondo de prestación de alimentos está en contacto con él y que ha devuelto los importes abonados por dicho fondo a la demandada, siempre teniendo en cuenta su capacidad económica (Conclusiones del Abogado General, Sr. M. Bobek, presentadas el 27 de febrero de 2020, FXc. GZ, C-41/19 (ECLI:EU:C:2020:132), apartado 22).

${ }^{7}$ Para un análisis de los foros de competencia judicial internacional del Reglamento 4/2009 vid., E. CAstellanos Ruiz, Derechos de alimentos, Aspectos internacionales y transfornterizos, Tirant lo Blanch, Valencia, 2017, pp. 47-66; J. CARRASCOsa González, “Alimentos”, en A.-L. Calvo Caravaca/ J. Carrascosa González, Tratado de Derecho internacional privado, Tomo II, Tirant lo Blanch, Valencia, 2020, pp. 2221-2230.

${ }^{8}$ Conclusiones del Abogado General, Sr. M. Bobek, presentadas el 27 de febrero de 2020, FX c. GZ, C-41/19 (ECLI:EU: C:2020:132), apartado 28.

${ }^{9}$ Conclusiones del Abogado General, Sr. M. Bobek, presentadas el 27 de febrero de 2020, FX c. GZ, C-41/19 (ECLI:EU: C:2020:132), apartado 23.

${ }^{10}$ Conclusiones del Abogado General, Sr. M. Bobek, presentadas el 27 de febrero de 2020, FX c. GZ, C-41/19 (ECLI:EU: C:2020:132), apartado 28 .

${ }^{11}$ STJUE 4 de junio de 2020, FX c. GZ, C-41/19 (ECLI:EU:C:2020:425), apartado 29.

${ }^{12}$ Conclusiones del Abogado General, Sr. M. Bobek, presentadas el 27 de febrero de 2020, FX c. GZ, C-41/19 (ECLI:EU: C:2020:132), apartado 30 . 
no es otra que, si los órganos jurisdiccionales alemanes son competentes para conocer de dicha demanda en virtud del Reglamento $4 / 2009^{13}$.

\section{Competencia para conocer de una demanda de oposición a la ejecución realizada contra una resolución de alimentos extranjera}

6. Como ya se ha adelantado, para determinar la competencia en relación con una demanda de oposición a la ejecución relizada por el deudor de alimentos -frente a la ejecución de una resolución dictada por el órgano jurisdiccional del Estado miembro de origen y mediante la que se ha declarado la existencia de dicho crédito- se procederá a analizar en primer lugar, el ámbito de aplicación del Reglamento 4/2009.

Una vez que se ha llegado a la conclusión de que la fase de ejecución de los alimentos entra dentro del ámbito de aplicación del Reglamento 4/2009, en segundo lugar, se pretende determinar si dicha demanda de oposición forma parte de los procedimientos de ejecución y, por tanto, está comprendida también en el ámbito de competencia de los órganos jurisdiccionales del Estado miembro de ejecución.

\section{1. Ámbito de aplicación del Reglamento 4/2009}

7. De forma acertada en la sentencia se concluye que en virtud de los Considerandos (10) y (11) y los arts. 1.1 y 2 del Reglamento 4/2009, dicho instrumento constituye un instrumento de la Unión Europea que agrupa las disposiciones sobre los conflictos de jurisdicción, los conflictos de leyes, el reconocimiento y la fuerza ejecutiva y la ejecución de las resoluciones judiciales en materia de obligaciones de alimentos derivadas de una relación familiar, de parentesco, matrimonio o afinidad ${ }^{14}$.

El legislador europeo quiso sustituir las disposiciones en materia de obligaciones de alimentos recogidas en el Reglamento 44/2001 relativo a la competencia judicial, el reconocimiento y la ejecución de resoluciones judiciales en materia civil y mercantil y predecesor del Reglamento 1215/2012, mediante disposiciones que, dada la especial urgencia en el pago de las deudas alimenticias, simplificaran el procedimiento ante el juez que sustancia la ejecución y lo hicieran más rápido ${ }^{15}$. Por lo que el Reglamento 4/2009 contiene un capítulo IV, bajo el título "Reconocimiento, fuerza ejecutiva y ejecución de las resoluciones", que regula precisamente la ejecución de las resoluciones de los órganos jurisdiccionales de los Estados miembros en materia de obligaciones de alimentos ${ }^{16}$.

En este sentido, el Reglamento 4/2009 constituye una lex especialis en materia de alimentos en lo que respecta a los tres sectores del Derecho internacional privado ${ }^{17}$. Esto también lo confirma el art. 1.2.e) y el Considerando (10) del Reglamento 1215/2012 que excluyen de su ámbito de aplicación material las obligaciones de alimentos ${ }^{18}$.

8. Esta primera conclusión de la sentencia objeto de análisis parece obvia, pues al tratarse de un litigio en materia de alimentos, es lógico deducir que para su resolución se aplique el Reglamento 4/2009. Sin embargo, si se tienen en cuenta los diferentes argumentos de las distintas partes, que recoge en sus Conclusiones el Abogado General para fundamentar dicha aseveración, no se trata de una

\footnotetext{
${ }^{13}$ Conclusiones del Abogado General, Sr. M. Bobek, presentadas el 27 de febrero de 2020, FX c. GZ, C-41/19 (ECLI:EU: C:2020:132), apartado 2.

${ }^{14}$ STJUE 4 de junio de 2020, FXc. GZ, C-41/19 (ECLI:EU:C:2020:425), apartado 31.

${ }^{15}$ Reglamento (CE) núm. 44/2001 del Consejo, de 22 de diciembre de 2000 (DO núm. L 12, 16 enero 2001), relativo a la competencia judicial, el reconocimiento y la ejecución de resoluciones judiciales en materia civil y mercantil. Vid. STJUE 9 de febrero de 2017, M.S. C. P.S., C-283/16, (ECLI:EU:C:2017:104), apartado 32.

${ }^{16}$ STJUE 4 de junio de 2020, FX c. GZ, C-41/19 (ECLI:EU:C:2020:425), apartado 32.

${ }^{17}$ Vid. E. Castellanos Ruiz, Derechos de alimentos, Aspectos internacionales y transfornterizos, Tirant lo Blanch, Valencia, 2017, p. 23; J. Carrascosa González, “Alimentos”, en A.-L. Calvo Caravaca/ J. Carrascosa González, Tratado de Derecho internacional privado, Tomo II, Tirant lo Blanch, Valencia, 2020, p. 2216.

${ }^{18}$ STJUE 4 de junio de 2020, FX c. GZ, C-41/19 (ECLI:EU:C:2020:425), apartado 33.
} 
cuestión baladí, ya que el litigio que ha dado lugar a esta sentencia es una demanda de oposición a la ejecución realizada contra una resolución de alimentos extranjera, la cual no es sencilla de calificar. Pues bien, antes de llegar a esta conclusión tanto por el Abogado General, como el Tribunal de Justicia de la Unión Europea, las hipótesis que se plantearon fueron tres, que se pasan a detallar.

\section{La demanda de oposición a la ejecución de una sentencia de alimentos es considerada una} demanda en materia de alimentos, siendo de aplicación los arts. 3 y 4 del Reglamento 4/2009. Esta es la posición defendida por el Gobierno portugués, el tribunal alemán que conoce del asunto y la demandada. En su opinión como consecuencia de la finalidad tuitiva del Reglamento 4/2009 en relación con los acreedores de alimentos, son de aplicación los foros de competencia judicial del Reglamento 4/2009 ${ }^{19}$.

Dicho órgano jurisdiccional señala que una parte de la doctrina alemana considera que la demanda de oposición a la ejecución prevista en el art. 767 de la ZPO debe calificarse de acción en materia de obligaciones de alimentos, en el sentido del Reglamento 4/2009 ${ }^{20}$. Además, como la demanda de oposición a la ejecución equivale, funcionalmente, a una acción de reducción de la deuda alimenticia objeto del título ejecutivo, es considerada una acción de modificación, que tal y como señala el art. 8 del Reglamento 4/2009, está sujeta a los criterios en materia de competencia. Si bien, se debe matizar que en virtud del art. 8.1, los tribunales competentes serían los polacos para realizar dicha modificación de sentencia, porque el acreedor de alimentos sigue residiendo en Polonia. Al no haber cambiado de residencia habitual el acreedor de alimentos, no es posible que se activen los foros de competencia, tal y como pretende el tribunal alemán al afirmar que los tribunales polacos estarían en mejor situación de comprobar las alegaciones del demandante, en virtud de los foros recogidos en los arts. 3.a) y 3.b) del Reglamento 4/200921. En base a estas dos afirmaciones contradictorias del tribunal alemán, cabe preguntarse si éste considera que la demanda de oposición a la ejecución contra una resolución de alimentos extranjera debe ser calificada como una acción de modificación de alimentos o no.

En cualquier caso, con independencia de los matices señalados, para el tribunal alemán esta es la única postura compatible con el objetivo perseguido por el Reglamento, que no es otro que el de garantizar que el acreedor de alimentos esté protegido y en una posición privilegiada desde el punto de vista de las reglas de competencia. Todo ello con el fin último de que dicho acreedor no tenga que defenderse, ante los tribunales del Estado miembro de ejecución de la deuda, frente a una demanda de oposición a la ejecución que, en su opinión, tiene por objeto excepciones de fondo referidas a dicha deuda ${ }^{22}$.

Por lo tanto, el tribunal alemán que conoce del asunto considera que en virtud del Reglamento 4/2009 no es competente para conocer del asunto, porque carece de foro de competencia judicial internacional.

10. La demanda de oposición a la ejecución no forma parte de las acciones en materia de obligaciones de alimentos, en el sentido del Reglamento 4/2009. Esta posición es la adoptada por el Gobierno polaco, que sañala que el Reglamento 4/2009 no regula la competencia en la fase de ejecución. Como los derechos y obligaciones reconocidos en la resolución en materia de alimentos no resultan afectados, la demanda de oposición a la ejecución no versa sobre materia de alimentos y, por tanto, se rige por el art. 24.5 del Reglamento 1215/2012 23 .

\footnotetext{
${ }^{19}$ Conclusiones del Abogado General, Sr. M. Bobek, presentadas el 27 de febrero de 2020, FX c. GZ, C-41/19 (ECLI:EU: C:2020:132), apartado 35 .

${ }^{20} \mathrm{El}$ art. 767 de la Zivilprozessordnung (Ley de Enjuiciamiento Civil), en su versión aplicable al litigio principal (BGB1. 2007 I, p. 1781; en lo sucesivo, ZPO), recoge la "Demanda de oposición a la ejecución" (STJUE 4 de junio de 2020, FX c. GZ, C-41/19 (ECLI:EU:C:2020:425), apartado 15)

${ }^{21}$ Vid. Conclusiones del Abogado General, Sr. M. Bobek, presentadas el 27 de febrero de 2020, FX c. GZ, C-41/19 (ECLI:EU:C:2020:132), apartado 28. Para un mayor análisis del art. 8 del Reglamento 4/2009 vid., E. Castellanos Ruiz, Derechos de alimentos, Aspectos internacionales y transfornterizos, Tirant lo Blanch, Valencia, 2017, pp. 64-66; J. CARRASCOSA González, “Alimentos”, en A.-L. Calvo Caravaca/ J. Carrascosa González, Tratado de Derecho internacional privado, Tomo II, Tirant lo Blanch, Valencia, 2020, p. 2230.

${ }^{22}$ STJUE 4 de junio de 2020,FX c. GZ, C-41/19 (ECLI:EU:C:2020:425), apartado 25.

${ }^{23} \mathrm{Se}$ debe aclarar que, en respuesta a una pregunta formulada por el Tribunal de Justicia, el Gobierno polaco cambió su postura en relación con la norma aplicable ratione temporis y que la disposición que sería de aplicación sería el art. 22.5 del Re-
} 
En esta misma línea interpretativa, la doctrina dominante en Alemania -contraria a la primera tesis seguida por el órgano jurisdiccional alemán que conoce de asunto- considera que la demanda de oposición a la ejecución no forma parte de las acciones en materia de obligaciones de alimentos, en el sentido del Reglamento 4/2009, debido a que el objetivo de la protección jurídica solicitada se refiere sólo a la ejecución de la deuda, mientras que la existencia del título original no se ve modificada. El legislador alemán considera que los tribunales del Estado miembro de ejecución de una deuda alimenticia son competentes para conocer de dicha demanda de oposición a la ejecución, tal y como contempla el art. 767 de la $Z P O$, en la que el deudor puede formular excepciones relativas a la propia deuda ${ }^{24}$. Por esa razón, en el caso de que esta portura de parte de la doctrina alemana fuese la correcta, el tribunal alemán plantea la segunda cuestión prejudicial relativa a si la demanda de oposición a la ejecución puede ser considerada un "procedimiento en materia de ejecución de resoluciones judiciales", en el sentido del art. 24.5 del Reglamento 1215/2012, tal y como afirma el Gobierno polaco ${ }^{25}$.

Del planteamiento de esta segunda cuestión prejudicial podría parecer que el tribunal alemán no sabe a qué norma acogerse de los distintos instrumentos internacionales vigentes, para declararse competentes, porque existe una disposición de su normativa de producción interna, el art. 767 de la ZPO, contempla específicamente la demanda de oposición a la ejecución, en la que el deudor puede plantear excepciones en relación a la deuda. El motivo es que de las explicaciones que contiene el proyecto de la $A U G$ (Ley sobre el Cobro Internacional de Pensiones Alimenticias de Alemania), en relación con su art. 66, se deduce que el legislador alemán recurrió al art. 22.5 del Reglamento 44/2001 como disposición supletoria con respecto a la ejecución de resoluciones en materia de obligaciones de alimentos, pues dicho instrumento internacional no contiene la exclusión que sí contempla el Reglamento 1215/2012. Sin embargo, en este litigio no se cumple el ámbito de aplicación temporal del Reglamento 44/2001, por lo que no se puede acudir su art. 22.5, ni siquiera con carácter supletorio ${ }^{26}$.

11. La demanda de oposición a la ejecución entra dentro del ámbito de aplicación del Reglamento 4/2009, pero en virtud del art. 41.1. Dicha postura es la que siguen el Gobierno alemán y la Comisión, que consideran que, en contra de la posición del órgano jurisdiccional alemán, ello no implica la falta de competencia de dicho tribunal, sino más bien todo lo contrario, que este sí es competente para conocer del asunto, pues se trata de la ejecución de una resolución de alimentos. Añaden además, que bajo esta hipótesis, ni el Reglamento 1215/2012, ni el Reglamento 44/2001 son aplicables a este litigio ${ }^{27}$.

Esta posición, que también es la adoptada por el demandante, es la que que en opinión del Abogado General es la acertada. En resumen, sólo es aplicable a dicha demanda de oposición a la ejecución el Reglamento 4/2009, pero esto no implica que el órgano jurisdiccional alemán ante el que se presenta la demanda, no sea competente ${ }^{28}$.

12. Efectivamente, esta última interpretación es la que tiene una base más solida y más coherente con los objetivos del Reglamento 4/2009. Y así se recoge en la sentencia del Tribunal de Justicia, que señala que está comprendido en el ámbito de aplicación del Reglamento 4/2009, un litigio que se

glamento 44/2001 (Conclusiones del Abogado General, Sr. M. Bobek, presentadas el 27 de febrero de 2020, FX c. GZ, C-41/19 (ECLI:EU:C:2020:132), apartado 36).

${ }^{24}$ STJUE 4 de junio de 2020, FXc. GZ, C-41/19 (ECLI:EU:C:2020:425), apartado 26.

${ }^{25}$ STJUE 4 de junio de 2020, FX c. GZ, C-41/19 (ECLI:EU:C:2020:425), apartado 27.

${ }^{26}$ De acuerdo con el art. 75.2 del Reglamento 4/2009: "el [Reglamento n.o 44/2001] seguirá siendo de aplicación a los procedimientos de reconocimiento y ejecución que estén en curso en la fecha de aplicación del presente Reglamento". Dicha fecha es, de conformidad con el art. 76 del Reglamento 4/2009, el 18 de junio de 2011. El procedimiento de reconocimiento y ejecución del asunto en cuestión no estaba en curso en dicha fecha, pues se inició el 27 de julio de 2016, en un momento en que también habría sido aplicable ratione temporis el Reglamento 1215/2012 -pues, con arreglo a su art. 81, está en vigor desde el 10 de enero de 2015-. Sobre el ámbito de aplicación temporal del Reglamento 1215/2012 vid., STJUE 9 de marzo de 2017, Pula Parking, C-551/15, (ECLI:EU:C:2017:193), apartados 25-28. Vid. Conclusiones del Abogado General, Sr. M. Bobek, presentadas el 27 de febrero de 2020, FX c. GZ, C-41/19 (ECLI:EU:C:2020:132), nota a pie (12).

${ }^{27}$ Conclusiones del Abogado General, Sr. M. Bobek, presentadas el 27 de febrero de 2020, FX c. GZ, C-41/19 (ECLI:EU: C:2020:132), apartado 37 .

${ }^{28}$ Conclusiones del Abogado General, Sr. M. Bobek, presentadas el 27 de febrero de 2020, FX c. GZ, C-41/19 (ECLI:EU: C:2020:132), apartado 38 . 
inicia ante un órgano jurisdiccional de un Estado miembro (el Estado miembro de ejecución), que tiene por objeto la ejecución de una resolución, declarada ejecutiva en dicho Estado miembro y dictada por un órgano jurisdiccional de otro Estado miembro (el Estado miembro de origen), en materia de obligaciones de alimentos derivadas de una relación familiar ${ }^{29}$. Si bien este asunto estaría incluido en el ámbito del capítulo IV del Reglamento 4/2009, que recoge normas específicas dedicadas al reconocimiento y ejecución de resoluciones en materia de obligaciones de alimentos. Con lo cual, no son de aplicación las normas de competencia de su capítulo II $^{30}$.

Para el Tribunal de Justicia aunque el capítulo IV del Reglamento no contenga ninguna norma de competencia específica en relación a la ejecución, se puede afirmar que un norma de ese tipo es inherente al sistema de dicho Reglamento ${ }^{31}$. En general, la competencia internacional para la ejecución les corresponde a los órganos jurisdiccionales del Estado miembro donde se solicita la ejecución ${ }^{32}$.

Para la Comisión, el hecho de que el Reglamento 1215/2012 contenga una norma expresa para la ejecución, mientras que el Reglamento 4/2009 no la contempla, es debido a la estructura del Reglamento $1215 / 2012$, que establece varios criterios de competencia exclusiva ${ }^{33}$. Sin embargo, el Reglamento 4/2009 no crea ninguna competencia exclusiva. Siguiendo esta línea argumental, el Abogado General se pregunta: “¿A qué otra jurisdicción habría de corresponderle la competencia para la ejecución, si no es al Estado miembro donde esta se solicita?" ${ }^{34}$. Además, la aplicación supletoria del Reglamento 1215/2012 en este caso resultaría bastante complicada, porque las obligaciones de alimentos están expresamente excluidas de su ámbito de aplicación; por no mencionar que su aplicación supletoria no aporta ningún valor añadido ${ }^{35}$.

Por lo tanto, dentro del ámbito de aplicación del Reglamento 4/2009 se encuentra una demanda de oposición a la ejecución de una resolución extranjera sobre alimentos, pues en vitud del art. 41.1 del mismo se establece que: "a reserva de lo dispuesto en el presente Reglamento, el procedimiento de ejecución de las resoluciones dictadas en otro Estado miembro se regirá por el Derecho del Estado miembro de ejecución". Además, añade el precepto, "las resoluciones dictadas en un Estado miembro que tengan fuerza ejecutiva en el Estado miembro de ejecución serán ejecutadas en este en las mismas condiciones que si se hubieran dictado en dicho Estado miembro de ejecución". Esta disposición no tendría sentido si no le correspondiese a los órganos jurisdiccionales del Estado miembro donde se solicita la ejecución, la competencia para dicha ejecución ${ }^{36}$.

A continuación, se debe resolver la cuestión de si la demanda de oposición a la ejecución basada, concretamente, en la liquidación de la deuda forma parte de los procedimientos de ejecución y, por consiguiente, son competentes para conocer del asunto los órganos jurisdiccionales del Estado miembro de ejecución, es decir, los tribunales alemanes ${ }^{37}$.

\footnotetext{
${ }^{29}$ Para un mayor análisis del ámbito de aplicación material del Reglamento 4/2009 vid., E. CAstellanos Ruz, Derechos de alimentos, Aspectos internacionales y transfornterizos, Tirant lo Blanch, Valencia, 2017, pp. 25-35; J. CARRASCosa GonZÁlez, "Alimentos", en A.-L. Calvo Caravaca/ J. Carrascosa González, Tratado de Derecho internacional privado, Tomo II, Tirant lo Blanch, Valencia, 2020, pp. 2218-2220. Vid. Conclusiones del Abogado General, Sr. M. Bobek, presentadas el 27 de febrero de 2020, FX c. GZ, C-41/19 (ECLI:EU:C:2020:132), apartados 39 y 40; STJUE 4 de junio de 2020, FX c. GZ, C-41/19 (ECLI:EU:C:2020:425), apartado 34.

${ }^{30}$ Conclusiones del Abogado General, Sr. M. Bobek, presentadas el 27 de febrero de 2020, FX c. GZ, C-41/19 (ECLI:EU: C:2020:132), apartado 42 .

${ }^{31}$ Conclusiones del Abogado General, Sr. M. Bobek, presentadas el 27 de febrero de 2020, FX c. GZ, C-41/19 (ECLI:EU: C:2020:132), apartado 43 .

${ }^{32}$ Para una fundamentación más detallada de este argumento realizada por el Gobierno polaco vid., Conclusiones del Abogado General, Sr. M. Bobek, presentadas el 27 de febrero de 2020, FX c. GZ, C-41/19 (ECLI:EU:C:2020:132), apartado 44.

${ }^{33}$ El art. 24.5 del Reglamento 1215/2012 señala expresamente que: "en materia de ejecución de las resoluciones judiciales, los órganos jurisdiccionales del Estado miembro del lugar de ejecución".

${ }^{34}$ Conclusiones del Abogado General, Sr. M. Bobek, presentadas el 27 de febrero de 2020, FX c. GZ, C-41/19 (ECLI:EU: C:2020:132), apartado 47.

${ }^{35}$ Conclusiones del Abogado General, Sr. M. Bobek, presentadas el 27 de febrero de 2020, FX c. GZ, C-41/19 (ECLI:EU: C:2020:132), apartado 46.

${ }^{36}$ Conclusiones del Abogado General, Sr. M. Bobek, presentadas el 27 de febrero de 2020, FX c. GZ, C-41/19 (ECLI:EU: C:2020:132), apartado 48 .

${ }^{37}$ Conclusiones del Abogado General, Sr. M. Bobek, presentadas el 27 de febrero de 2020, FX c. GZ, C-41/19 (ECLI:EU: C:2020:132), apartado 49 .
} 


\section{Tribunales competentes en relación a una demanda de oposición a la ejecución basada en la liquidación de la deuda de alimentos (art. 41.1 Reglamento 4/2009)}

13. La demanda de oposición a la ejecución en este litigo se basa en la alegación del demandante de que la deuda declarada en la resolución en materia de alimentos ya ha sido liquidada, al menos en su mayor parte. Por un lado, el demandante ya ha pagado parte del importe adeudado directamente a la demandada. Por otro lado, el Fondo de Prestación de Alimentos polaco ha pagado parte de la deuda en nombre del demandante, aunque el deudor ha reembolsado dichos importes en la medida de su capacidad económica. Según el demandante, el litigio se produce porque la demandada no reconoce que el importe pagado por el Fondo de Prestación de Alimentos polaco se corresponda con la deuda del demandante ${ }^{38}$.

La cuestión fundamental que se plantea es si una demanda de oposición a la ejecución basada en la liquidación de la deuda debe considerarse, a efectos de competencia, comprendida entre los procedimientos de ejecución ${ }^{39}$. Tras analizar la jurisprudencia del Tribunal de Justicia sobre el Convenio de Bruselas y el Reglamento 44/2001, el Abogado General considera que las mismas líneas argumentales seguidas por dicho Tribunal son válidas con respecto a las demandas de oposición a la ejecución en el ámbito del Reglamento 4/2009 ${ }^{40}$. Aunque la intervención del Fondo de Prestación de Alimentos polaco en el pago de la deuda ha añadido algo de complejidad al asunto, de dicho análisis se desprende que básicamente se deben cumplir dos requisitos para que los órganos jurisdiccionales del Estado miembro de ejecución gocen de competencia ${ }^{41}$. En primer lugar, y el más importante, que ese tipo de demanda esté intrínsecamente vinculada a la ejecución. En segundo lugar, que no se invoque ningún motivo que hubiese podido ser formulado ante los órganos jurisdiccionales polacos durante el procedimiento que finalizó con la resolución en materia de alimentos; ni tampoco, ningún motivo de denegación o revocación del otorgamiento de ejecución ante los órganos jurisdiccionales alemanes.

14. Demanda estrechamente vinculada a la ejecución. El Tribunal de Justicia ya declaró en otro litigio que la demanda de oposición a la ejecución prevista en el artículo 767 de la ZPO mantiene un estrecho vínculo con el procedimiento de ejecución ${ }^{42}$. Por lo tanto, cuando una demanda de oposición tiene relación con una demanda de ejecución de una resolución en materia de obligaciones de alimentos, está comprendida, al igual que esta última, en el ámbito de aplicación del Reglamento 4/2009 ${ }^{43}$.

Efectivamente, tal y como ya se ha señalado, en el capítulo IV del Reglamento 4/2009 no se hace referencia expresamente a la competencia en la fase de ejecución, de forma que no se contempla concretamente la demanda de oposición a la ejecución basada en la liquidación de una deuda de alimentos. Sin embargo, de su art. 41.1 se desprende implícitamente que el conocimiento de una demanda que tenga un vínculo estrecho con el procedimiento de ejecución de una resolución dictada por un órgano jurisdiccional del Estado miembro de origen, es competencia de los órganos jurisdiccionales del Estado miembro de ejecución, al igual que sucede con la propia demanda de ejecución de dicha resolución ${ }^{44}$.

\footnotetext{
${ }^{38}$ Conclusiones del Abogado General, Sr. M. Bobek, presentadas el 27 de febrero de 2020, FX c. GZ, C-41/19 (ECLI:EU: C:2020:132), apartado 73.

${ }^{39}$ Conclusiones del Abogado General, Sr. M. Bobek, presentadas el 27 de febrero de 2020, FX c. GZ, C-41/19 (ECLI:EU: C:2020:132), apartado 50 .

${ }^{40}$ Convenio de Bruselas de 1968 (DO núm. L 299, 31 diciembre 1972), relativo a la competencia judicial y a la ejecución de resoluciones judiciales en materia civil y mercantil. Para un análisis detallado de las líneas argumentales arriba mencionadas vid., Conclusiones del Abogado General, Sr. M. Bobek, presentadas el 27 de febrero de 2020, FX c. GZ, C-41/19 (ECLI:EU: C:2020:132), apartados 51-72.

${ }^{41}$ Conclusiones del Abogado General, Sr. M. Bobek, presentadas el 27 de febrero de 2020, FX c. GZ, C-41/19 (ECLI:EU: C:2020:132), apartado 50.

${ }^{42}$ Concretamente en la STJUE de 4 de julio de 1985, AS-Autoteile Service, 220/84, (ECLI: EU:C:1985:302), apartado 12. Conclusiones del Abogado General, Sr. M. Bobek, presentadas el 27 de febrero de 2020, FX c. GZ, C-41/19 (ECLI:EU:C:2020:132), apartado 52; STJUE 4 de junio de 2020, FX c. GZ, C-41/19 (ECLI:EU:C:2020:425), apartado 35.

${ }^{43}$ STJUE 4 de junio de 2020, FXc. GZ, C-41/19 (ECLI:EU:C:2020:425), apartado 35.

${ }^{44}$ STJUE 4 de junio de 2020, FXc. GZ, C-41/19 (ECLI:EU:C:2020:425), apartados 36-38. Tal y como sucede en otros instrumentos internacionales, que no incluyen expresamente normas sobre ejecución. Así, en el asunto Hoffmann, tras reconocer que el Convenio de Bruselas no contenía normas específicas sobre la ejecución, el Tribunal de Justicia declaró que "la ejecución de una resolución extranjera respecto a la cual se hayan realizado las formalidades necesarias para que sea ejecutiva
} 
El TJUE señala al respecto que iría en contra de los objetivos de simplicidad y celeridad que persigue el Reglamento 4/2009 que, habiéndose presentado ante los tribunales del Estado miembro de ejecución una demanda de ejecución de una resolución declarada ejecutiva, estos tengan que declinar su competencia con respecto a una demanda de oposición a la ejecución, en favor del tribunal del Estado miembro de origen, porque en virtud del art. 3.b) del Reglamento 4/2009 -que recoge el foro de la residencia habitual del acreedor de alimentos-, es el más apropiado para garantizar la protección del acreedor de dichos alimentos ${ }^{45}$. El Tribunal de Justicia ya ha declarado en otros asuntos que la proximidad entre el órgano jurisdiccional competente y el acreedor de alimentos no es el único objetivo del Reglamento 4/200946. En este sentido, el Reglamento también pretende garantizar una buena administración de justicia, no solamente desde el punto de vista de la optimización de la organización judicial, sino también desde la perspectiva del interés de ambas partes, que puedan tener un acceso simplificado a la justicia y unas reglas de competencia previsibles ${ }^{47}$. Además, la declinación de la competencia en favor de los tribunales del Estado miembro de origen no tendría como consecuencia facilitar al máximo el cobro de los créditos de alimentos internacionales -que es uno de sus objetivos prioritarios-; sino más bien todo lo contrario, pues alargaría y entorpecería excesivamente el procedimiento, lo que supondría un pérdida de tiempo y dinero considerables para ambas partes ${ }^{48}$.

Por lo tanto, una de las Conclusiones más importantes del Abogado General es que: "aunque el objetivo de proteger al acreedor de alimentos como parte más débil está claramente reconocido por el Reglamento 4/2009, a mi parecer ello no debe llevar a abandonar uno de los principios básicos comunes a todos los instrumentos de cooperación civil: que las medidas relativas a la ejecución de las resoluciones le incumben al Estado miembro de ejecución"49.

15. Implicación en la demanda del Fondo de Prestación de Alimentos. Como ya se ha mencionado, la demanda de oposición a la ejecución se basa en que el demandante ya ha pagado en gran parte la deuda alimenticia, incluso parte de ella a través del Fondo de Prestación de Alimentos. Para el Abogado General, la intervención del fondo de prestación de alimentos polaco podría ser la causa por la

se practica de acuerdo con las normas de procedimiento del Derecho nacional del juez que conoce de la ejecución, incluidas las referentes a los recursos". Esta postura fue confirmada posteriormente por el TJUE en la sentencia Prism Investments, esta vez en relación con el Reglamento 44/2001, al afirmar que un motivo basado en el cumplimiento de la obligación "puede estar sujeto al examen del órgano jurisdiccional de ejecución del Estado miembro requerido", pues, "según reiterada jurisprudencia, una vez que una resolución queda integrada en el ordenamiento jurídico del Estado miembro requerido, las normas nacionales de este último Estado relativas a la ejecución se aplican de la misma manera que a las resoluciones adoptadas por los órganos jurisdiccionales nacionales". Los límites a la competencia de los órganos jurisdiccionales del Estado miembro de ejecución con respecto a ciertas solicitudes de oposición a la ejecución han sido recientemente confirmados con respecto al Reglamento 1215/2012, en la sentencia Reitbauer y otros. El Tribunal de Justicia rechazó la pretensión del demandante -una declaración de que el crédito había dejado de existir al haberse compensado con un derecho del deudor- porque consideró que se excedía de las cuestiones relativas a la ejecución, por lo que, no presentaba el grado de proximidad necesario que justificase la aplicación de la norma de la competencia exclusiva del art. 24.5 del Reglamento 1215/2012 (Conclusiones del Abogado General, Sr. M. Bobek, presentadas el 27 de febrero de 2020, FX c. GZ, C-41/19 (ECLI:EU:C:2020:132), apartados 53-59). Vid. STJUE 4 de febrero de 1988, Hoffmann, 145/86, (ECLI:EU:C:1988:61), apartados 27 y 28); STJUE 13 de octubre de 2011, Prism Investments, C139/10 (ECLI:EU:C:2011:653), apartados 37 y 40; STJUE 10 julio 2019, Reitbauer y otros, C722/17, (ECLI:EU:C:2019:577), apartados 54-55.

${ }^{45}$ STJUE 4 de junio de 2020, FX c. GZ, C-41/19 (ECLI:EU:C:2020:425), apartado 39. Efectivamente con el objetivo específico del Reglamento 4/2009 de proteger al acreedor de alimentos como parte más débil, las normas de competencia que contiene están concebidas para facilitar la defensa de su crédito. Vid. STJUE 18 diciembre 2014, Sanders y Huber, C-400/13 y C-408/13 (ECLI:EU:C:2014:2461), apartados 26-28.

${ }^{46}$ STJUE 18 diciembre 2014, Sanders y Huber, C-400/13 y C-408/13 (ECLI:EU:C:2014:2461), apartado 40. Vid. STJUE 4 de junio de 2020, FX c. GZ, C-41/19 (ECLI:EU:C:2020:425), apartado 40.

${ }^{47}$ STJUE 18 diciembre 2014, Sanders y Huber, C-400/13 y C-408/13 (ECLI:EU:C:2014:2461), apartado 29. Vid. STJUE 4 de junio de 2020, FX c. GZ, C-41/19 (ECLI:EU:C:2020:425), apartado 40.

${ }^{48}$ STJUE 18 diciembre 2014, Sanders y Huber, C-400/13 y C-408/13 (ECLI:EU:C:2014:2461), apartado 41. Vid. STJUE 4 de junio de 2020, FX c. GZ, C-41/19 (ECLI:EU:C:2020:425), apartado 41.

${ }^{49}$ Conclusiones del Abogado General, Sr. M. Bobek, presentadas el 27 de febrero de 2020, FX c. GZ, C-41/19 (ECLI:EU: C:2020:132), apartado 64 . 
que el órgano jurisdiccional alemán había considerado que los órganos jurisdiccionales polacos estaban mejor situados para resolver sobre la liquidación de la deuda ${ }^{50}$.

Sin embargo, desde el punto de vista de la deuda a cargo del deudor de alimentos, la intervención del Fondo afecta únicamente a la forma en que se satisface la deuda, y no tiene incidencia alguna sobre el fondo de la resolución en materia de alimentos ${ }^{51}$. Si bien es cierto que, en los procedimientos transfronterizos en materia de alimentos, la implicación de los organismos públicos, como el Fondo de Prestación de Alimentos polaco, puede añadir cierta complejidad probatoria ${ }^{52}$.

Además, la liquidación de la deuda es uno de los motivos típicamente reconocidos en la fase de ejecución ${ }^{53}$. Por otra parte, el Considerando (30), frase $2^{\mathrm{a}}$, del Reglamento 4/2009 establece que la liquidación de una deuda por el deudor en el momento de la ejecución figura entre los motivos de denegación o suspensión de la ejecución previstos por el Derecho nacional que no son incompatibles con dicho Reglamento ${ }^{54}$.

Por lo tanto, la liquidación de la deuda, invocada por el deudor para fundamentar la demanda de oposición a la ejecución ante el órgano jurisdiccional del Estado miembro de ejecución, cuando ya existe una resolución extranjera, no persigue ni modificar esa resolución o que se adopte una nueva resolución en ese último Estado miembro, en el sentido del art. 8 del Reglamento 4/2009; ni tampoco solicitar la revisión en cuanto al fondo de dicha resolución en ese Estado, en el sentido su art. $42^{55}$.

No obstante, aunque no parece ser el caso de la liquidación la deuda, no todos los motivos se pueden invocar en una demanda de oposición a la ejecución, sino que existen limitaciones con respecto a los motivos que se pueden alegar en la fase de ejecución.

16. Limitaciones de los motivos utilizados en la demanda. El Abogado General señala que no cabe formular ante los tribunales competentes para realizar la ejecución unos motivos que podrían haberse invocado por la vía de recurso contra la resolución de otorgamiento de ejecución; y con mayor razón, también quedan excluidos aquellos motivos que pudieran haberse invocado en el procedimiento inicial ${ }^{56}$.

En esta misma línea, el TJUE aclara que el art. 66 de la $A U G$, que es la disposición nacional aplicable, permite que el deudor de alimentos únicamente pueda formular objeciones basadas en cir-

\footnotetext{
${ }^{50}$ Conclusiones del Abogado General, Sr. M. Bobek, presentadas el 27 de febrero de 2020, FX c. GZ, C-41/19 (ECLI:EU: C:2020:132), apartado 79.

${ }^{51}$ STJUE 4 de junio de 2020, FX c. GZ, C-41/19 (ECLI:EU:C:2020:425), apartado 49. El Gobierno polaco señaló que el Fondo de Prestación de Alimentos polaco interviene por ley y actúa como deudor sustituto frente al acreedor: la deuda se extingue en cuanto a los importes pagados por el fondo en nombre del deudor de alimentos, y este debe reembolsar dichos importes directamente al fondo. Este sistema es coherente con la función de los organismos públicos, que con frecuencia pagan prestaciones a los acreedores de alimentos en lugar de los deudores, tal y como reconoce el artículo 64 del Reglamento 4/2009 (Conclusiones del Abogado General, Sr. M. Bobek, presentadas el 27 de febrero de 2020, FX c. GZ, C-41/19 (ECLI:EU:C:2020:132), apartado 80). Es cierto que sobre determinadas disposiciones del Reglamento 4/2009 existen dudas sobre su aplicación cuando interviene el Fondo de Prestación de Alimentos. Existe un debate sobre la cuestión se saber si el foro de la residencia habitual del acreedor de alimentos -el antiguo foro del art. 5.2 del Reglamento 44/2001 estaba pensado para proteger al acreedor de alimentos-, puede emplearse cuando el demandante no es el acreedor de alimentos, sino una institución pública que pide el reembolso de los alimentos a otras personas, normalmente al deudor que tenía que suministrar tales alimentos. La jurisprudencia del TJCE era contraria, si bien a partir de la aplicación del Reglamento 4/2009 la cuestión no es tan evidente, porque el art. 68.2 de dicho instrumento internacional podría permitir utilizar dicho foro a un organismo público que actúa en lugar de una persona física acreedora de los alimentos (E. CASTELlanos Ruiz, Derechos de alimentos, Aspectos internacionales y transfornterizos, Tirant lo Blanch, Valencia, 2017, pp. 57-58; J. Carrascosa GonzÁlez, “Alimentos”, en A.-L. Calvo Caravaca/ J. Carrascosa GonzÁLEZ, Tratado de Derecho internacional privado, Tomo II, Tirant lo Blanch, Valencia, 2020, p. 2226).

${ }^{52}$ STJUE 4 de junio de 2020,FX c. GZ, C-41/19 (ECLI:EU:C:2020:425), apartado 50. Para conocer la solución propuesta por el Abogado General, en cuanto al problema probatorio, vid. Conclusiones del Abogado General, Sr. M. Bobek, presentadas el 27 de febrero de 2020, FX c. GZ, C-41/19 (ECLI:EU:C:2020:132), apartado 81.

${ }^{53}$ Conclusiones del Abogado General, Sr. M. Bobek, presentadas el 27 de febrero de 2020, FX c. GZ, C-41/19 (ECLI:EU: C:2020:132), apartado 78 .

${ }^{54}$ STJUE 4 de junio de 2020, FX c. GZ, C-41/19 (ECLI:EU:C:2020:425), apartado 45. Para un análisis mayor del contexto dentro del Reglamento 4/2009 en el que figura dicho Considerando (30), párrafo $2^{\circ}$, vid., Conclusiones del Abogado General, Sr. M. Bobek, presentadas el 27 de febrero de 2020, FX c. GZ, C-41/19 (ECLI:EU:C:2020:132), apartado 82.

${ }^{55}$ STJUE 4 de junio de 2020, FX c. GZ, C-41/19 (ECLI:EU:C:2020:425), apartado 46.

${ }^{56}$ Conclusiones del Abogado General, Sr. M. Bobek, presentadas el 27 de febrero de 2020, FX c. GZ, C-41/19 (ECLI:EU: C:2020:132), apartado 60 .
} 
cunstancias que se hayan producido después de la adopción de la resolución de alimentos. Por lo tanto, tal disposición excluye que puedan presentarse para fundamentar válidamente la demanda de oposición a la ejecución circunstancias que hubieran podido ser invocadas por el deudor de alimentos ante el tribunal del Estado miembro de origen ${ }^{57}$. El Abogado General añade, por tanto, además que tiene que tratarse de motivos que no pudieron invocarse por la vía del recurso contra la resolución de otorgamiento de ejecución ante los órganos jurisdiccionales alemanes ${ }^{58}$. Dichos órganos sólo pueden denegar o revocar dicho otorgamiento por los motivos mencionados en el art. 24 del Reglamento 4/2009, entre los cuales no se menciona la liquidación de la deuda ${ }^{59}$.

17. De todo el análisis previo, tanto el Abogado General como el Tribunal de Justicia confirman que la liquidación de la deuda, que es el motivo en el que se basa la demanda de oposición a la ejecución, está estrechamente vinculado al procedimiento de ejecución y no puede considerarse una acción dirigida a modificar una resolución en materia de alimentos en el sentido del art. 8 del Reglamento 4/2009, ni tampoco a revisar el fondo de la resolución en el sentido del art. 42 de dicho Reglamento ${ }^{60}$. Si bien cuando haya un alto grado de vinculación de la demanda a la ejecución será bastante habitual que no se trate de una acción dirigida a modificar una resolución de alimentos, ni tampoco a revisar el fondo de la resolución. Por esta razón, el TJUE en su fallo únicamente menciona que para que un motivo pueda invocarse de forma válida en la fase de ejecución, tiene que estar estrechamente vinculado a la ejecución.

En efecto, el TJUE establece que la demanda de oposición a la ejecución basada en la liquidación de la deuda está estrechamente vinculada al procedimiento de ejecución, en la medida en que únicamente tiene por objeto impugnar la cantidad por la que todavía puede ejecutarse la resolución que otorga alimentos al acreedor. Para ello, se tendrán en cuenta las pruebas aportadas por el deudor con respecto a la liquidación de la deuda que alega, pruebas cuya admisibilidad y fundamento tiene que apreciar el órgano jurisdiccional del Estado miembro de ejecución ${ }^{61}$.

Además, dicho órgano jurisdiccional del Estado miembro de ejecución tendrá en cuenta las limitaciones previstas en las disposiciones nacionales aplicables que garanticen que: los motivos que habrían podido invocarse ante los órganos jurisdiccionales del Estado miembro de origen, no puedan ser invocados posteriormente ante los órganos jurisdiccionales del Estado miembro de ejecución; ni que se trate de ninguno de los motivos de denegación o revocación del otorgamiento de ejecución que podrían haberse alegado ante los órganos jurisdiccionales del Estado miembro de ejecución y que están recogidos en el art. 24 del Reglamento ${ }^{62}$.

18. En definitiva, una demanda de oposición a la ejecución basada en la liquidación de la deuda respeta los límites que establecen el Reglamento 4/2009 y la jurisprudencia del Tribunal de Justicia a la norma general (art. 41.1), según la cual la competencia para conocer de acciones estrechamente vinculadas con la ejecución les corresponde a los órganos jurisdiccionales del Estado miembro donde se solicita la ejecución ${ }^{63}$.

Ahora bien, en la misma línea que el Abogado General, el Tribunal de Justicia concluye que, aunque es competencia de dicho tribunal proporcionar los elementos de interpretación del Reglamento 4/2009 que sean útiles para el órgano jurisdiccional alemán en relación con tal motivo de oposición,

\footnotetext{
${ }^{57}$ STJUE 4 de junio de 2020, FX c. GZ, C-41/19 (ECLI:EU:C:2020:425), apartado 48.

${ }^{58}$ Conclusiones del Abogado General, Sr. M. Bobek, presentadas el 27 de febrero de 2020, FX c. GZ, C-41/19 (ECLI:EU: C:2020:132), apartado 83.

${ }^{59}$ Art. 1 Reglamento 4/2009.

${ }^{60}$ Conclusiones del Abogado General, Sr. M. Bobek, presentadas el 27 de febrero de 2020, FX c. GZ, C-41/19 (ECLI:EU: C:2020:132), apartado 75; STJUE 4 de junio de 2020, FX c. GZ, C-41/19 (ECLI:EU:C:2020:425), apartado 46.

${ }^{61}$ STJUE 4 de junio de 2020, $F X$ c. GZ, C-41/19 (ECLI:EU:C:2020:425), apartado 47.

${ }^{62}$ Conclusiones del Abogado General, Sr. M. Bobek, presentadas el 27 de febrero de 2020, FX c. GZ, C-41/19 (ECLI:EU: C:2020:132), apartado 83; STJUE 4 de junio de 2020, FX c. GZ, C-41/19 (ECLI:EU:C:2020:425), apartado 48.

${ }^{63}$ Conclusiones del Abogado General, Sr. M. Bobek, presentadas el 27 de febrero de 2020, FX c. GZ, C-41/19 (ECLI:EU: C:2020:132), apartado 74; STJUE 4 de junio de 2020, FX c. GZ, C-41/19 (ECLI:EU:C:2020:425), apartado 42.
} 
corresponde exclusivamente a este último órgano jurisdiccional apreciar los hechos y las pruebas presentadas por las partes en el litigio principal con las que sustentan sus pretensiones ${ }^{64}$.

\section{Conclusiones}

19. El fallo de la sentencia afirma que está comprendida dentro del ámbito de aplicación del Reglamento 4/2009, y más concretamente, en el de la competencia interncional de los órganos jurisdiccionales del Estado miembro de ejecución, una demanda de oposición a la ejecución por parte del deudor de alimentos contra una resolución de reclamación de alimentos, dictada por un órgano jurisdiccional del Estado miembro de origen, siempre que dicha demanda esté estrechamente vinculada al procedimiento principal ${ }^{65}$.

Ahora bien, de acuerdo con el art. 41.1 del Reglamento 4/2009 y las disposiciones del Derecho nacional pertinentes, corresponde al órgano jurisdiccional del Estado miembro de ejecución, pronunciarse sobre la admisibilidad y el fundamento de las pruebas aportadas por el deudor de alimentos para demostrar que ha pagado en gran parte su deuda ${ }^{66}$.

20. La primera cuestión a solucionar es si una demanda de oposición a la ejecución entra dentro del ámbito de aplicación del Reglamento 4/2009. Precisamente porque no es una cuestión baladí, se plantean tres hipótesis.

En primer lugar, para el tribunal alemán, que es el que conoce del asunto, y para la demandada, la demanda de oposición a la ejecución es considerada una acción en materia de obligaciones de alimentos, por lo que como consecuencia de la finalidad tuitiva del Reglamento 4/2009 en relación con los acreedores de alimentos, son de aplicación los foros de competencia judicial del Reglamento 4/2009 a ese tipo de litigios.

En segundo lugar, el tribunal polaco y la doctrina dominante en Alemania consideran que la demanda de oposición a la ejecución no forma parte de las acciones en materia de obligaciones de alimentos, en el sentido del Reglamento 4/2009, debido a que el objetivo de la protección jurídica solicitada se refiere sólo a la ejecución de la deuda. Por esta razón, proponen la aplicación art. 24.5 del Reglamento 1215/2012, de forma que dicha demanda de oposición a la ejecución sea considerada un "procedimiento en materia de ejecución de resoluciones judiciales". En consecuencia, cuando se trata de la ejecución de resoluciones judiciales, son competentes los órganos jurisdiccionales del Estado miembro del lugar de ejecución.

Por último, la tercera propuesta realizada por el Gobierno alemán y la Comisión, es la que considera que la demanda de oposición a la ejecución de una resolución en materia de alimentos estaría dentro del ámbito del capítulo IV del Reglamento 4/2009, que recoge normas específicas dedicadas al reconocimiento y ejecución de resoluciones en materia de obligaciones de alimentos. Con lo cual, no son de aplicación las normas de competencia de su capítulo II. Esta es la hipótesis más sólida y más coherente con los objetivos del Reglamento 4/2009. Para la Comisión, el hecho de que el Reglamento 4/2009 no contenga una norma expresa para la ejecución, mientras que el Reglamento 1215/2012 sí la contemple, es debido a la estructura de éste último, que establece varios criterios de competencia exclusiva. Además, no se debe olvidar que las obligaciones de alimentos están expresamente excluidas del ámbito de aplicación del Reglamento 1215/2012 ${ }^{67}$.

\footnotetext{
${ }^{64}$ STJUE 4 de junio de 2020, FX c. GZ, C-41/19 (ECLI:EU:C:2020:425), apartado 44. El Abogado General hace concretamente dos puntualizaciones a su conclusión: $1^{\text {a }}$ ) Que el análisis y la conclusión a la que llega se refieren exclusivamente al motivo de oposición basado en la liquidación de la deuda; $2^{\mathrm{a}}$ ) Que, más allá de este motivo concreto, no se hace valoración alguna sobre la compatibilidad general del artículo 767 de la $Z P O$ con el Derecho de la Unión. (Conclusiones del Abogado General, Sr. M. Bobek, presentadas el 27 de febrero de 2020, FX c. GZ, C-41/19 (ECLI:EU:C:2020:132), apartado 85).

${ }^{65}$ STJUE 4 de junio de 2020, $F X$ c. GZ, C-41/19 (ECLI:EU:C:2020:425), apartado 51.

${ }^{66}$ STJUE 4 de junio de 2020, $F X$ c. GZ, C-41/19 (ECLI:EU:C:2020:425), apartado 51.

${ }^{67}$ Conclusiones del Abogado General, Sr. M. Bobek, presentadas el 27 de febrero de 2020, FX c. GZ, C-41/19 (ECLI:EU: C:2020:132), apartado 46 .
} 
Por lo tanto, la primera conclusión importante a la que se llega es que la demanda de oposición a la ejecución se encuentra dentro de los procedimientos de ejecución, por lo que está dentro del ámbito de aplicación del Reglamento 4/2009, en virtud de su art. 41.1.

21. Se debe puntualizar que es bastante común que los tribunales de los Estados miembros planteen cuestiones prejudiciales, como las del litigio que nos ocupa, cuando el concepto no aparece expresamente en las normas de los instrumentos internacionales; pero que, sin embargo, ya sólo de la denominación de dicho instrumento, se puede deducir que el asunto entra dentro de su ámbito de aplicación.

Este ha sido por ejemplo el caso del asunto Vincent Pierre Oberle, en el que se planteaba un litigio en materia de sucesiones ${ }^{68}$. Pues bien, la cuestión surge porque en el Reglamento 650/2012 en materia sucesoria no existe una norma específica que regule la competencia en materia de expedición de certificados sucesorios nacionales ${ }^{69}$. Sin embargo, dicho instrumento internacional sí que contempla una regulación específica relativa a la competencia en materia de expedición de certificados sucesorios europeos (art. 64 Reglamento 650/2012). Pues bien, ante la "aparente laguna legal" en relación con los certificados sucesorios nacionales, se debe determinar, si dentro del concepto de "totalidad de la sucesión" -que indica el ámbito de aplicación del Reglamento-, se encuentran dichos certificados. Pues bien, el Tribunal de Justicia determina que los certificados sucesorios nacionales se encuentran dentro del ámbito de aplicación del Reglamentos 650/2012, pues considera que se encuentran dentro del concepto de "totalidad de la sucesión"70.

Pues en el litigio que nos ocupa también se plantea la cuestión de si entra dentro del ámbito de aplicación del Reglamento 4/2009 una demanda de oposición a la ejecución de una resolución en materia de obligaciones de alimentos. La duda surge a pesar de que dicho instrumento internacional regula no sólo la competencia judidicial internacional y la ley aplicable, sino el reconocmiento de resoluciones judiciales en materia de alimentos; si bien el hecho de que uno de los objetivos del Reglamento fuera la protección del acreedor de alimentos, lleva a la paradoja de que los tribunales alemanes plantearan una cuestión prejudicial de este tipo. Pues bien, como no podía ser de otra manera, la respuesta ha sido que una demanda de oposición a la ejecución de una resolución en materia de alimentos se encuentra dentro de los procedimientos de ejecución, por lo que está dentro del ámbito de aplicación del Reglamento 4/2009.

Lo más inverosímil es que se plantee una cuestión prejudicial en relación a un aspecto que el propio instrumento internacional excluye expresamente de su ámbito de aplicación, como ha sucedido en el presente asunto, con el Reglamento 1215/2012. Pues bien, aunque el Reglamento 1215/2012, en su art. 1.2.e), excluye de las materias objeto de su regulación a las obligaciones de alimentos, el tribunal alemán plantea dudas en relación a este extremo. Si bien como ya se ha comentado, se debió a un error en la ratione temporis del Reglamento 1215/2012, y en realidad el tribunal alemán planteaba la aplicación supletoria del Reglamento 44/2001, tal y como lo establecían sus normas de producción interna. En cualquier caso, como ya se ha comentado, el Tribunal de Justicia ha aclarado este punto y ha reiterado que el Reglamento 1215/2012 excluye de su ámbito de aplicación los litigios en materia de alimentos.

22. Otro aspecto relevante a destacar es que tal y como señala el Abogado General, la conclusión de que según la cual los órganos jurisdiccionales del Estado miembro donde se solicita la ejecución, en principio, deben ser competentes para conocer de las demandas de oposición a la ejecución está respetando las garantías jurisdiccionales específicas que ofrece el Reglamento 4/2009; eso sí, siempre que se tenga en cuenta de las limitaciones ya establecidas por la jurisprudencia del Tribunal de Justicia en relación con el Convenio de Bruselas de 1968, el Reglamento 44/2001 y el Reglamento 1215/2012 .

\footnotetext{
${ }^{68}$ Sentencia del TJUE 21 junio 2018, Vincent Pierre Oberle, C-20/17 (ECLI:EU:C:2018:485).

${ }^{69}$ Reglamento (UE) núm. 650/2012 del Parlamento Europeo y del Consejo, de 4 de julio de 2012 (DOUE núm. L 201, 27 julio 2012), relativo a la competencia, la ley aplicable, el reconocimiento y la ejecución de las resoluciones, a la aceptación y la ejecución de los documentos públicos en materia de sucesiones mortis causa y a la creación de un certificado sucesorio europeo.

${ }^{70} \mathrm{Vid}$. M.-J. Castellanos Ruiz, "Competencia internacional en materia de expedición de certificados sucesorios: A propósito de la Sentencia del TJUE 21 junio 2018, Vincent Pierre Oberle, C-20/17”, Cuadernos de Derecho Transnacional (CDT), vol. 12, no 1 , marzo 2020, pp. 473-511.

${ }^{71}$ Conclusiones del Abogado General, Sr. M. Bobek, presentadas el 27 de febrero de 2020, FX c. GZ, C-41/19 (ECLI:EU:C:2020:132), apartado 66.
} 
En primer lugar, la vinculación de la demanda de oposición a la ejecución es el aspecto más importante a tener en cuenta, de forma que, la liquidación de la deuda está conectada en gran medida con la ejecución, pues únicamente tiene por objeto impugnar la cantidad por la que aún puede ejecutarse la resolución que otorga alimentos al acreedor. Por lo tanto, la liquidación de la deuda no persigue ni modificar esa resolución o que se adopte una nueva resolución en el Estado miembro de ejecución, en el sentido del art. 8 del Reglamento 4/2009; ni tampoco solicitar la revisión en cuanto al fondo de dicha resolución en ese Estado, en el sentido su art. 42.

Además, el hecho de que intervenga el Fondo de Prestación de Alimentos no tiene ninguna incidencia sobre el fondo de la resolución en materia de alimentos, sino que afecta únicamente a la forma en que se satisface la deuda y que puede añadir cierta complejidad probatoria.

23. Además, los órganos jurisdiccionales del Estado miembro de ejecución tendrán en cuenta las limitaciones previstas en las disposiciones nacionales aplicables, en virtud de las cuales, no cabe formular ante dichos tribunales unos motivos que podrían haberse invocado por la vía de recurso contra la resolución de otorgamiento de ejecución; y con mayor razón, también quedan excluidos aquellos motivos que pudieran haberse invocado en el procedimiento inicial.

Por último, se deberán tener en cuenta las pruebas aportadas por el deudor con respecto a la liquidación de la deuda que alega; siendo el órgano jurisdiccional del Estado miembro de ejecución el que tenga que aprecia la admisibilidad y el fundamento de dichas pruebas. 